\title{
Engineering a new access route to metastable polymorphs with electrical confinement
}

Aneesa J Al-Ani ${ }^{1}$, Carmelo Herdes ${ }^{2}$, Chick C Wilson ${ }^{1,3}$, Bernardo Castro-Dominguez ${ }^{1,2 *}$

${ }^{1}$ Centre for Sustainable Chemical Technologies (CSCT), University of Bath, Claverton Down, Bath BA2 7AY, United Kingdom.

${ }^{2}$ Centre for Advanced Separations Engineering, Department of Chemical Engineering, University of Bath, Claverton Down, Bath BA2 7AY, United Kingdom.

${ }^{3}$ Department of Chemistry, University of Bath, Claverton Down, Bath BA2 7AY, United Kingdom.

\section{SUPPORTING INFORMATION.}

\section{S.1 Results}

Table S.1.1 The experimental conditions under which PT-II was achieved reproducibly.

\begin{tabular}{|c|c|c|c|c|c|c|}
\hline Experiment & $\begin{array}{l}\text { Weight \% of meta- } \\
\text { cetamol (\%) }\end{array}$ & $\begin{array}{l}\text { Flow rate } \\
\left(m l h^{-1}\right)\end{array}$ & Solvent & $\begin{array}{l}\text { Electric field } \\
\left(\mathrm{kV} \mathrm{cm}^{-1}\right)\end{array}$ & $\begin{array}{l}\text { Polymorphic form } \\
\text { of paracetamol }\end{array}$ & $\begin{array}{l}\text { Optimal variable } \\
\text { value }\end{array}$ \\
\hline E1 & 50 & 0.15 & $\begin{array}{l}\text { IPA : } \mathrm{H} 2 \mathrm{O} \\
(40: 60)\end{array}$ & 1.00 & PCM-I & \multirow{4}{*}{$\underset{1}{\mathrm{EF}}=1.30 \mathrm{kV} \mathrm{cm}$} \\
\hline E2 & 25 & 0.25 & $\begin{array}{l}\text { IPA: } \mathrm{H} 2 \mathrm{O} \\
(40: 60)\end{array}$ & 1.25 & PCM-I & \\
\hline E3 & 25 & 0.25 & $\begin{array}{l}\text { IPA : } \mathrm{H} 2 \mathrm{O} \\
(40: 60)\end{array}$ & 1.29 & $\begin{array}{l}\text { PCM-I and PCM- } \\
\text { II }\end{array}$ & \\
\hline E4 & 50 & 0.15 & $\begin{array}{l}\text { IPA : } \mathrm{H} 2 \mathrm{O} \\
(40: 60)\end{array}$ & 1.30 & PCM-II & \\
\hline E5 & $50^{*}$ & 0.15 & $\begin{array}{l}\text { IPA : } \mathrm{H} 2 \mathrm{O} \\
(40: 60)\end{array}$ & 1.30 & PCM-II & $\begin{array}{l}\text { Independent on } \\
\text { solution satura- } \\
\text { tion }\end{array}$ \\
\hline E6 & 25 & 0.25 & $\begin{array}{l}\text { IPA: } \mathrm{H} 2 \mathrm{O} \\
(40: 60)\end{array}$ & 1.30 & PCM-II & \multirow{3}{*}{$\begin{array}{l}\text { Weight } \% \text { of } \\
\text { metacetamol = } \\
0.25 \%\end{array}$} \\
\hline E7 & 15 & 0.25 & $\begin{array}{l}\text { IPA: } \mathrm{H} 2 \mathrm{O} \\
(40: 60)\end{array}$ & 1.30 & PCM-I & \\
\hline E8 & 10 & 0.25 & $\begin{array}{l}\text { IPA: } \mathrm{H} 2 \mathrm{O} \\
(40: 60)\end{array}$ & 1.30 & PCM-I & \\
\hline E9 & 25 & 0.50 & $\begin{array}{l}\text { IPA: } \mathrm{H} 2 \mathrm{O} \\
(40: 60)\end{array}$ & 1.30 & PCM-I & $\begin{array}{l}\text { Flow rate }=0.25 \\
\mathrm{ml} \mathrm{h}^{-1}\end{array}$ \\
\hline
\end{tabular}

*This experiment used a less saturated solution of PCM and MCM, $0.75 \mathrm{~g}$ in $26 \mathrm{ml}$ of solvent. 


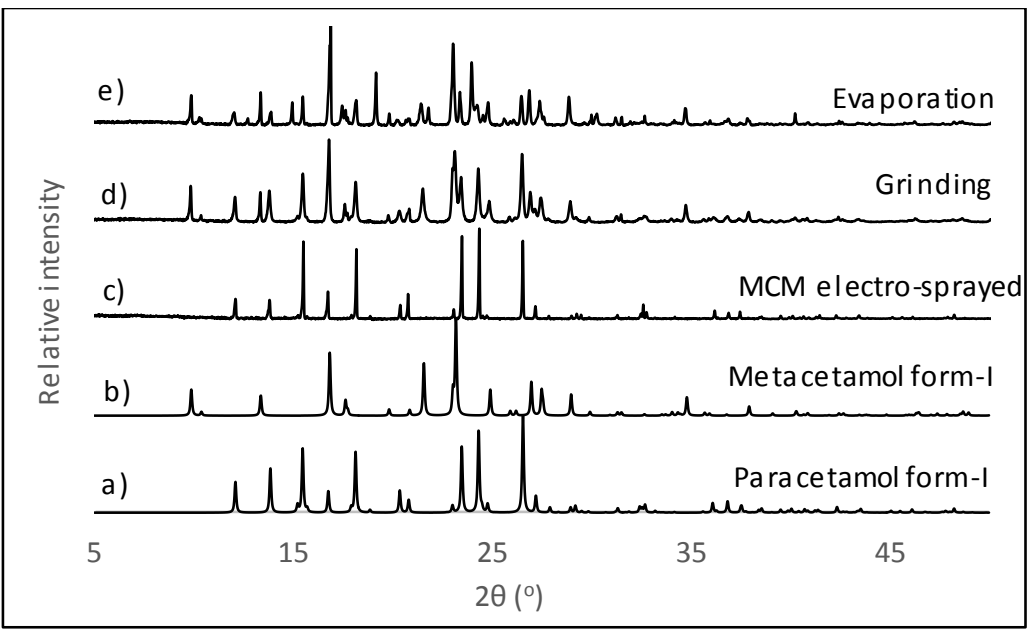

Figure S.1.1 The PXRD pattern of a) PT-I, CSD code = HXACAN01.b) MT, CSD code = MENSEE. c) The template molecule MT was subject to electro-spraying and not the API (PT).d) Grinding. e) Evaporative crystallization.

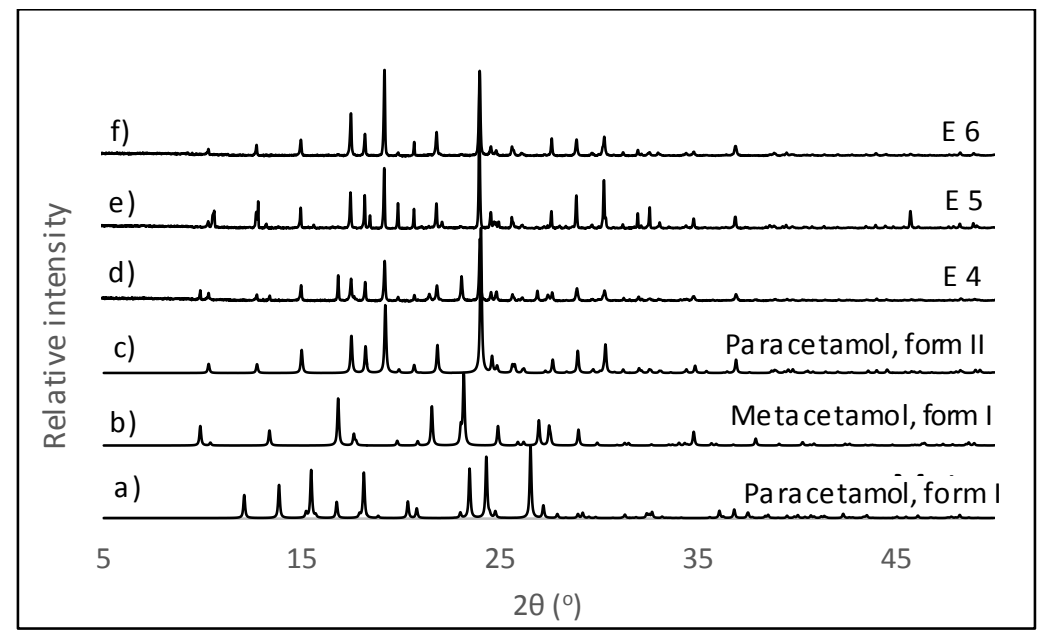

Figure S.1.2. The PXRD pattern of a) PCM-I, CSD code $=$ HXACAN01. b) MCM, CSD code = MENSEE. c) PCM-II CSD code $=$ HXACAN.d) Experiment 4 in table S1.e) Experiment 5 in table S1.f) Experiment 6 in table S1.

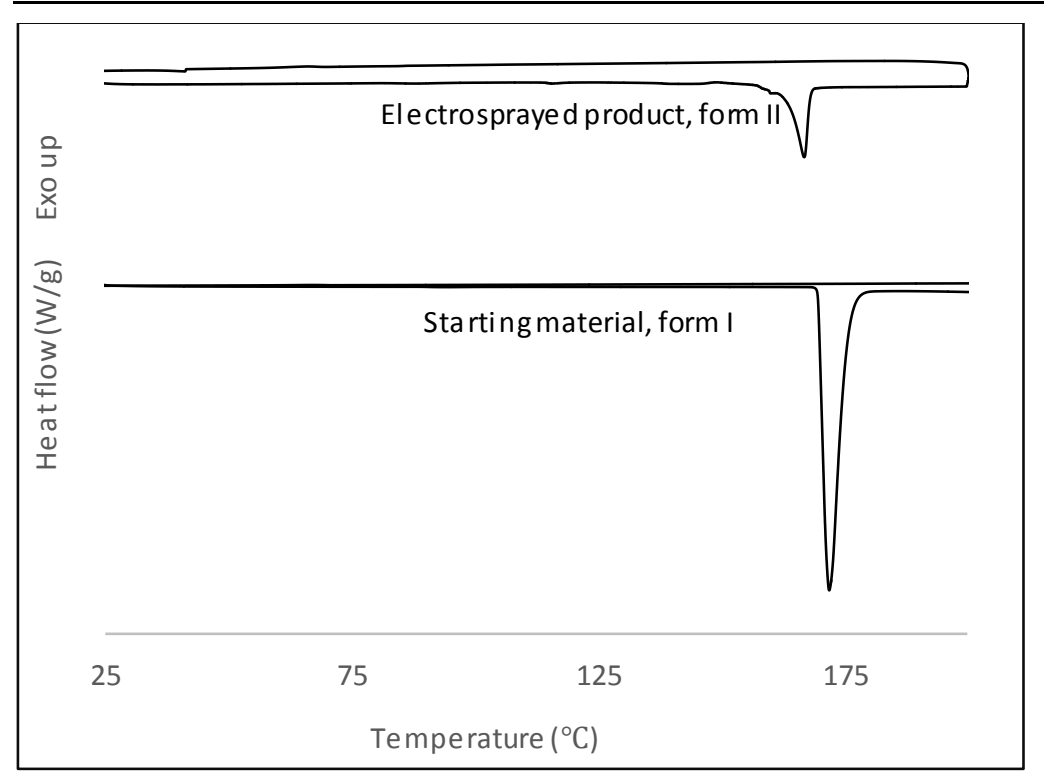

Figure S.1.3. The DSC plots of a) starting material PCM-

1. 


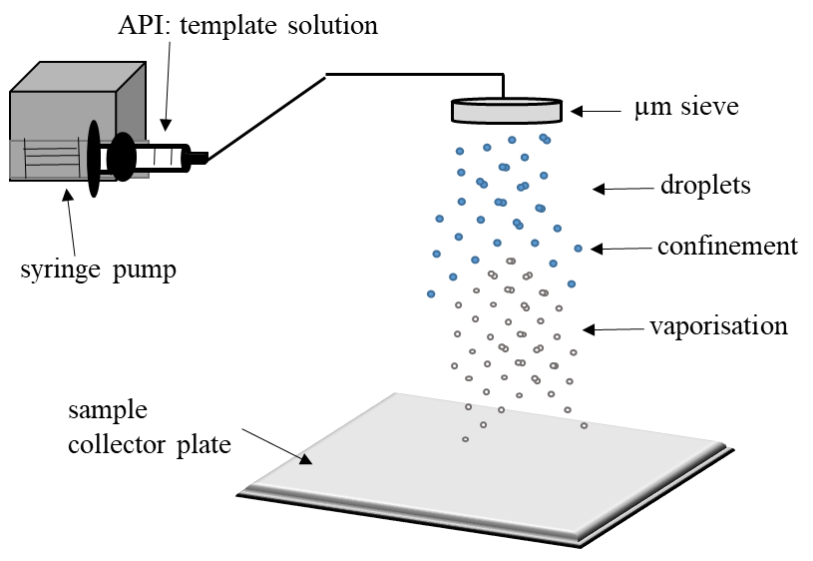

Figure S.1.4. A schematic of the confinement experimental in house set up.

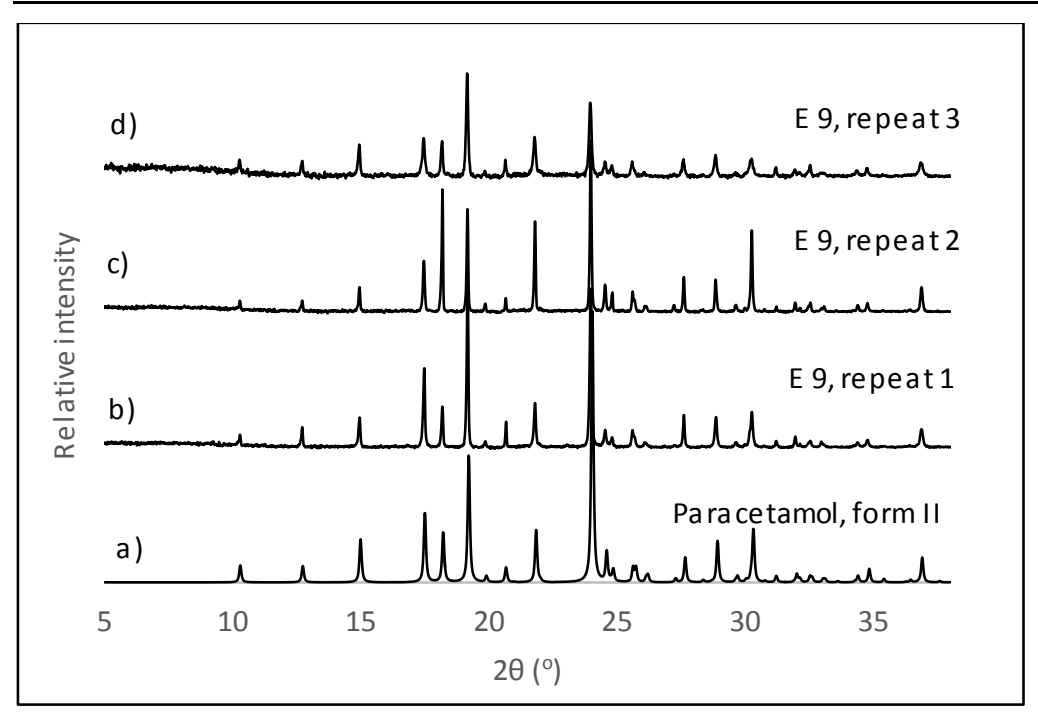

Figure S.1.5. The PXRD pattern of a) PCM-II, CSD code = HXACAN. b-d) Experiment 6 in table S1 repeated three times, corresponding to PCM form II.

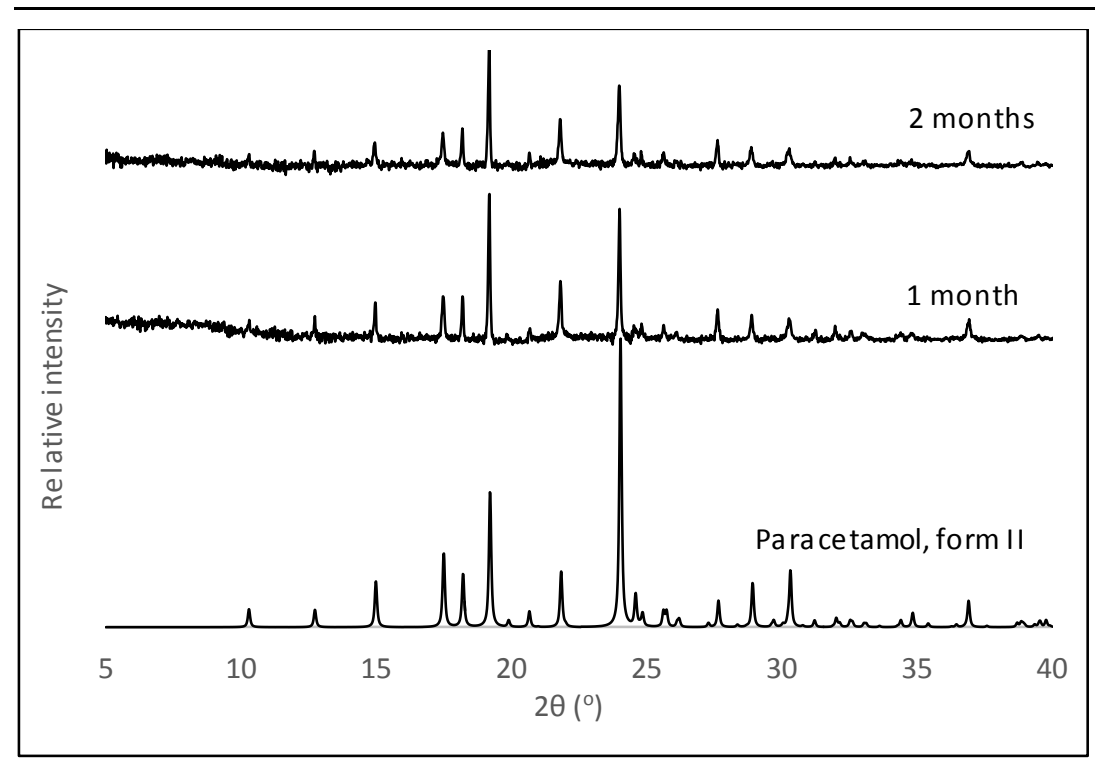


Figure S.1.6. The PXRD pattern of PCM-II, CSD code = HXACAN and experiment 6 in table S1 analyzed after 1 and 2 months of crystallization, corresponding to PCM form II.

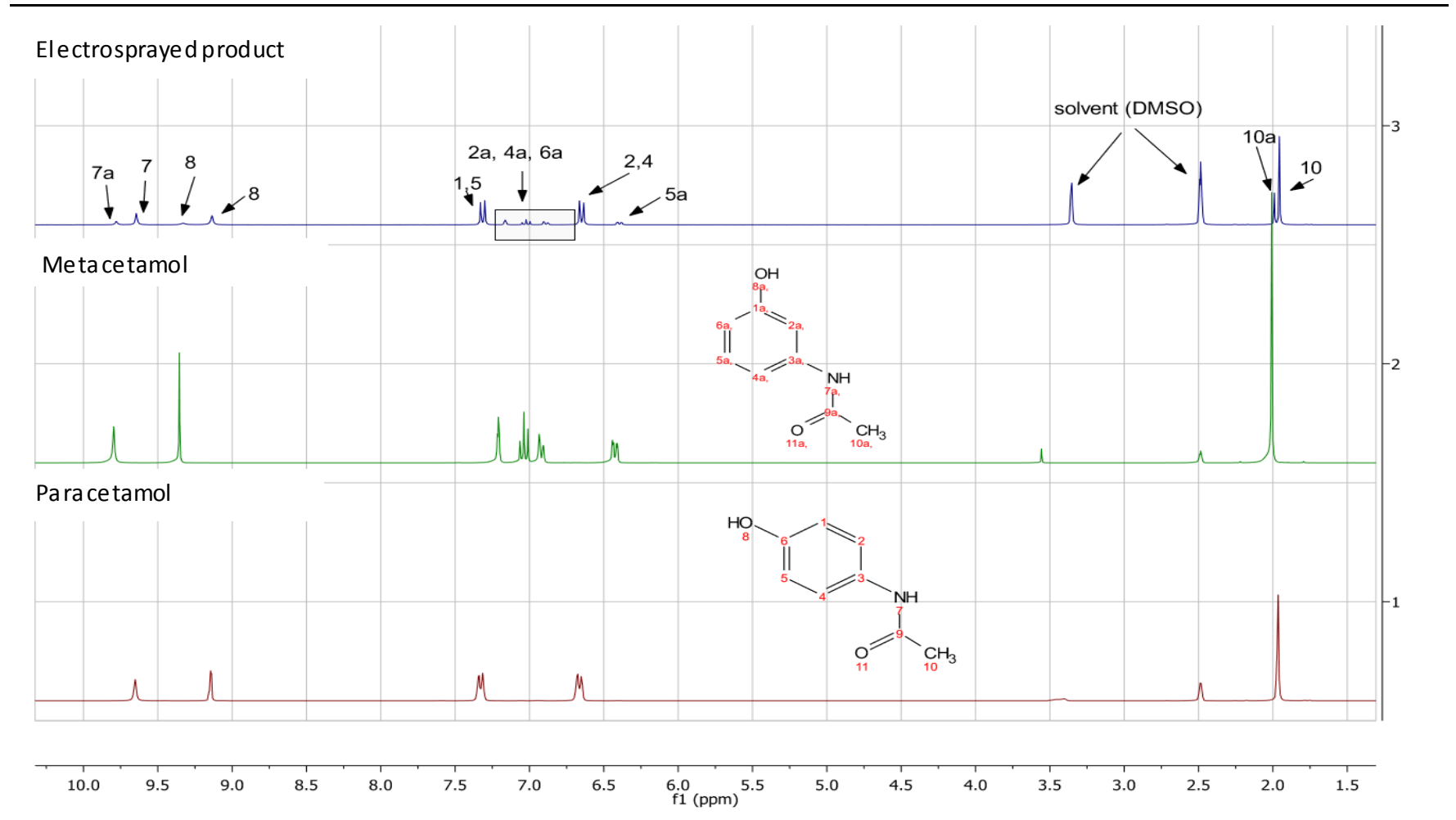

Figure S.1.7. The ${ }^{1} \mathrm{H}$ NMR for experiment 6 in table $S 1$, showing the presence of both PCM and MCM (3:1). 




Figure S.1.8. The PXRD pattern of PCM-I, CSD code = HXACAN01, PCM-II, CSD code = HXACAN and the effect of confinement corresponding to PCM-II with trace amounts of PCM-I observed in the PXRD pattern. The product was analyzed immediately and after 11 days.

\section{S.2 Molecular Dynamics Simulations}

For this study, an all-atoms description of the molecules was used, see figure S.2.1. All calculations were performed using the GROMACS simulation package version $2018.2^{2}$ in conjunction with the GROMOS 54A7 forcefield ${ }^{3}$ as implemented in the Automated Topology Builder ${ }^{4}$ (ATB) without any further tuning for this specific system. Hence the obtained results are a pure qualitative prediction. The author is aware of optimized force fields for independent components within the study, e.g. for the selected solvent mixture ${ }^{5}$, but the mix and match validation of all needed force fields escapes the scope and length of this revision.
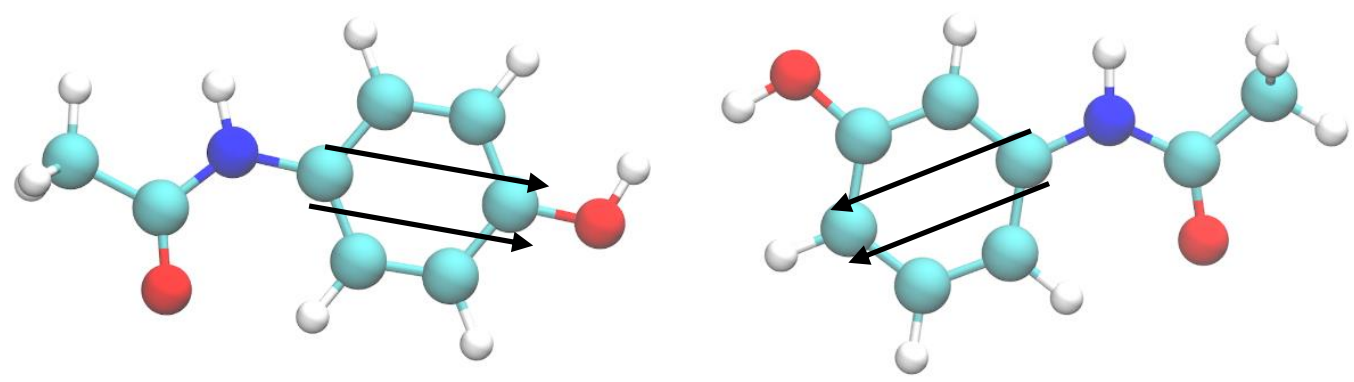

Figure S.2.1.Left) PCM molecule. Right) MCM molecule. The black arrow depicts the orientation vector in each API. 
Bulk simulation cell: 100 paracetamol, 300 metacetamol, 35700 isopropanol and 22600 water molecules were equilibrated under periodic boundary conditions in the isobaric-isothermal ensemble (NPT) at 293.15 K and 1 bar via the Nosé-Hoover thermostat with a time constant of 0.44 ps and a Parrinello-Rahman barostat with a time constant of 0.2 ps. Over $5 \mathrm{~ns}$ were needed to reach the equilibrated cell volume at $545 \mathrm{~nm}^{3}$ (Figure S.2.2). $10 \mathrm{~ns}$ production runs, to extract the result average values, under the NVT ensemble were performed with the Vrescale thermostat.

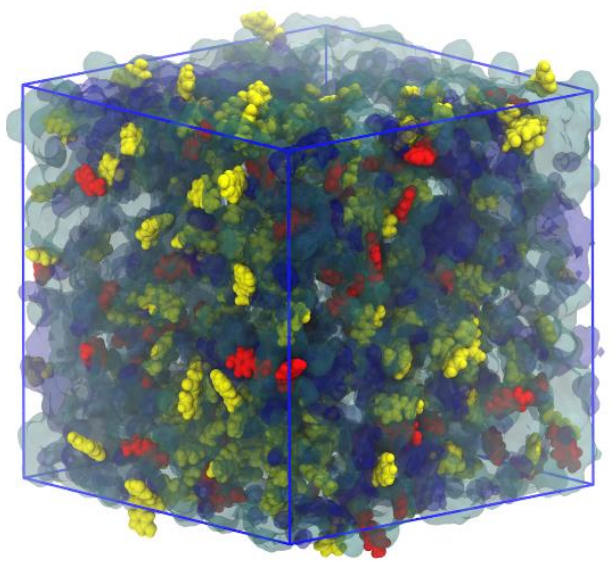

Figure S.2.2.Bulk system: PCM (red). MCM (yellow), IPA (cyan), H2O (blue)

Drop simulation cell: the equilibrated bulk cell (Figure S.2.2) was placed in the centre of a bigger vacuum cell of $13824 \mathrm{~nm}^{3}$, under an NVT ensemble (Figure S.2.3a). Instantaneously ( $<10 \mathrm{ps}$ ), the centred cubic cell adopted a quasi-spherical shape. Short after, the vacuum in the cell was replaced by the vapour in equilibrium with the isopropanol-water solvent nanodrop (Figure S.2.3b). Identical production runs were performed after $5 \mathrm{~ns}$ from the formation of the drop.


Figure S.2.3.a) Equilibrated bulk system in the centre of a vacuum NVT cell. 3b) Nanodrop in equilibrium with its vapour.

A constant electric field of $100 \mathrm{~V} / \mathrm{mm}$ was applied ${ }^{6}$ to the equilibrated bulk and drop systems in the $\mathrm{x}$-direction of the cell, averages were collected for $10 \mathrm{~ns}$ after $5 \mathrm{~ns}$ equilibration period for each cell.

\section{$\underline{\text { MD trajectory analysis tools }}$}


With and without the electric field:

Radial distribution functions (RDF) were calculated with the GROMACS post-processing subroutine gmx rdf, to explore the structure of the APIs in bulk. Mean-square displacements (MSD) of PCM and MCM were determined using the gmx msd, from which their self-diffusion coefficients were estimated. Average angle evolutions between the orientation vectors in the benzene ring of each API (Figure S.2.1) vs the z-axis were obtained via gmx gangle.

\section{$\underline{\text { MD results }}$}
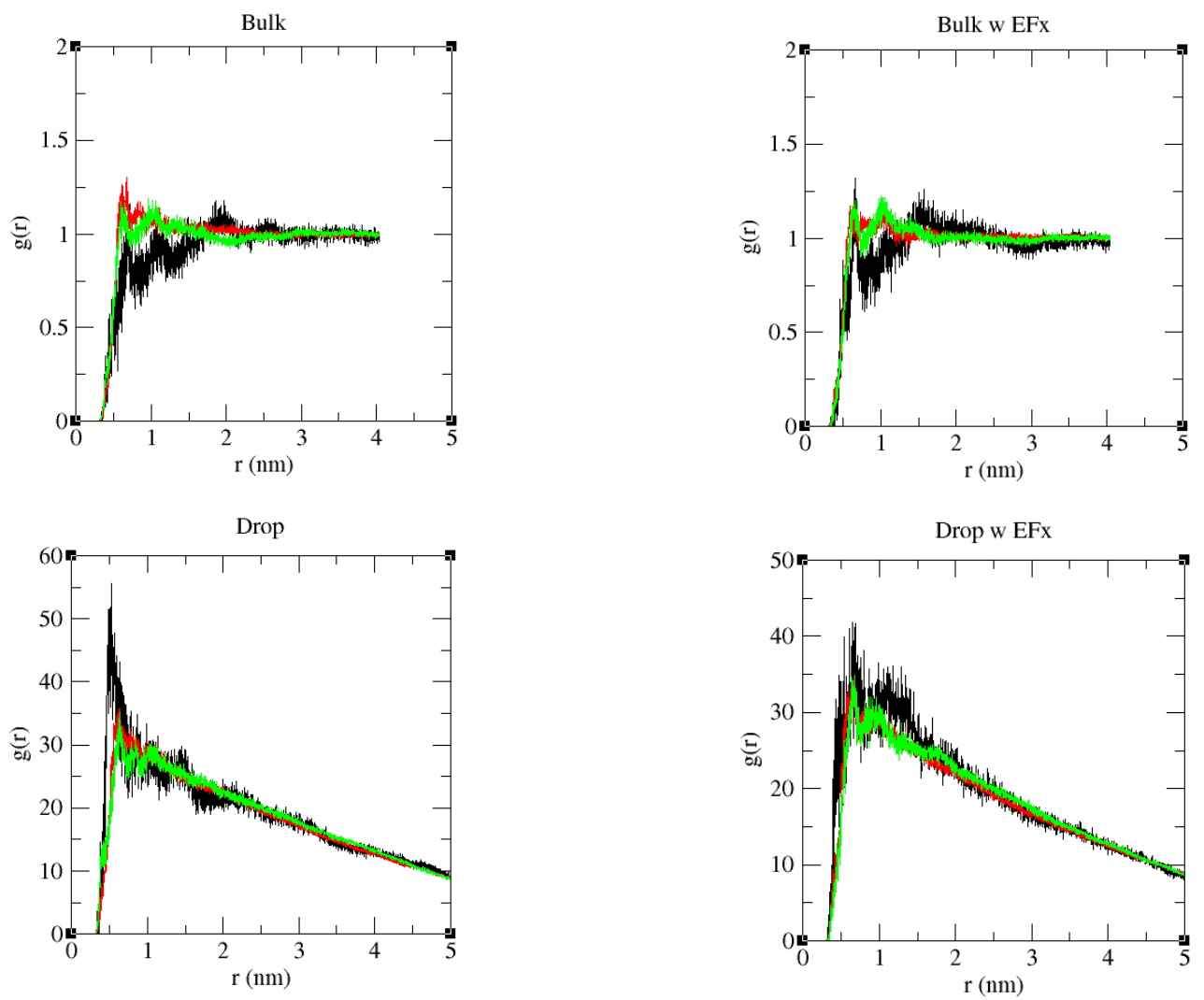

Figure S.2.1. Radial distribution functions of the centre of mass, PCM, MCM and PCM-MCM depicted as black, green and red lines respectively.


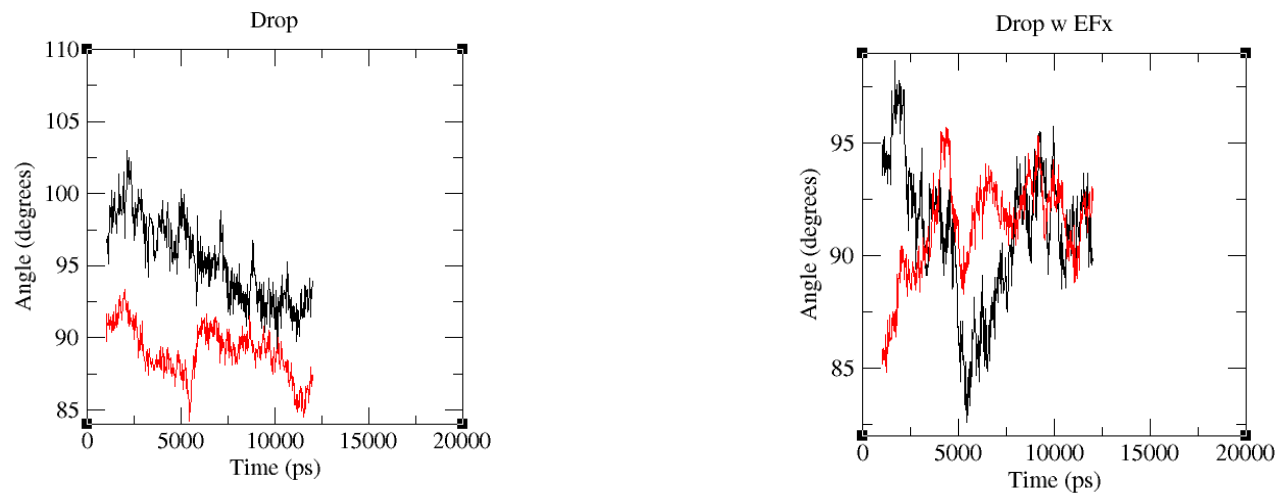

Figure S.2.2 APIs orientation vector angle evolution with respect to the z-axis. PMC and MCM are depicted in black and red lines respectively.

Table S.2.1 Self-diffusion coefficients for PCM and MCMin the bulk and drop systemsw/wo a constant electric field of $100 \mathrm{~V} / \mathrm{mm}$ in the $x$-direction of the cell. $x, y$ and $z$-components of the diffusion are also given.

\begin{tabular}{|c|c|c|}
\hline \multicolumn{3}{|c|}{ Self-diffusion $\left[10^{5} \mathrm{~cm}^{2} \mathrm{~s}^{-1}\right]$} \\
\hline & Bulk & Bulk $w E F x$ \\
\hline$P C M$ & $0.0276 \pm 0.0005$ & $0.0335 \pm 0.0010$ \\
\hline$P C M x$ & $0.0223 \pm 0.0028$ & $0.0395 \pm 0.0143$ \\
\hline PCMy & $0.0321 \pm 0.0011$ & $0.0273 \pm 0.0008$ \\
\hline$P C M z$ & $0.0283 \pm 0.0054$ & $0.0336 \pm 0.0104$ \\
\hline$M C M$ & $0.0223 \pm 0.0037$ & $0.0246 \pm 0.0038$ \\
\hline$M C M x$ & $0.0213 \pm 0.0014$ & $0.0282 \pm 0.0054$ \\
\hline$M C M y$ & $0.0238 \pm 0.0054$ & $0.0202 \pm 0.0055$ \\
\hline$M C M z$ & $0.0219 \pm 0.0070$ & $0.0253 \pm 0.0114$ \\
\hline & Drop & Drop w EFx \\
\hline$\overline{P C M}$ & $0.4213 \pm 0.1507$ & $-0.0823 \pm 0.9836$ \\
\hline$P C M x$ & $0.6090 \pm 0.5729$ & $-0.0405 \pm 0.0481$ \\
\hline PCMy & $0.5191 \pm 0.0824$ & $-0.0687 \pm 1.5030$ \\
\hline$P C M z$ & $0.1358 \pm 0.2030$ & $-0.1375 \pm 1.4000$ \\
\hline$M C M$ & $0.4288 \pm 0.1818$ & $-0.0827 \pm 1.0640$ \\
\hline$M C M x$ & $0.5900 \pm 0.6024$ & $-0.0410 \pm 0.0606$ \\
\hline$M C M y$ & $0.5717 \pm 0.1467$ & $-0.0808 \pm 1.5700$ \\
\hline$M C M z$ & $0.1246 \pm 0.2038$ & $-0.1263 \pm 1.5620$ \\
\hline
\end{tabular}

A negative diffusion is due to the aggregation of the APIs. 
- In the bulk environment, both APIs have similar diffusions and these values are slightly increased when a constant electric field is imposed. The rdf has a higher coordination number due to the aggregation of APIs. The PCM and MCM have similar orientation angle average values of 91.37 and 92.05 degrees respectively, with the electric field these values are almost maintained (91.32 and 92.01) but the fluctuation for PMC increased considerably.

- In the drop environment, both APIs have similar diffusions and increased in an order of magnitude with respect to the bulk. When a constant electric field is imposed APIs form clusters (i.e. negative diffusion values). The rdf has a similar structure with two well-defined coordination shells for PCM-MCM around 0.5 and $1.0 \mathrm{~nm}$. The PCM and MCM have different orientation angle trends that seem to stabilise around 92 and 87 degrees with respect to the z-axis, however, both values converge to 92 degrees in the presence of the electric field.

\section{S.3 Droplet diameter calculations and droplet charge}

To estimate the diameter of the droplets produced under electrospraying conditions, it is necessary to consider process parameters such as flowrate and voltage. Flowrates contribute to convective forces, while voltage to electrostatic forces. Consequently, at a constant voltage, the droplet size increases when flowrates are increased; while at constant flowrates, droplet size will reduced when subject to higher voltages. Nonetheless, when all forces are in balance, a constant droplet dimeter can be obtained and the following scale up equations can be applied ${ }^{7}$.

$$
\begin{aligned}
& d=d_{o}\left({ }^{Q} / Q_{0}\right)^{\frac{1}{2}} \\
& d_{0}=\left[\sigma \varepsilon_{0}{ }^{2} /\left(\rho K^{2}\right)\right]^{\frac{1}{3}} \\
& Q_{0}=\sigma \varepsilon_{0} /(\rho K)
\end{aligned}
$$

Table S.3.1. The values used in equation S.3 1-3, including the symbols meaning and units.

\begin{tabular}{|c|c|c|}
\hline Symbol & Meaning /Units & Value used / calculated \\
\hline$\rho$ & Density $/ \mathrm{kg} / \mathrm{m}^{3}$ & 912.6 \\
\hline$\sigma$ & Surface tension $/ \mathrm{N} / \mathrm{m}$ & 0.0524 \\
\hline $\mathrm{K}$ & Electric conductivity $/ \mathrm{S} / \mathrm{m}$ & 0.0001824 \\
\hline$\varepsilon_{0}$ & Electric permittivity $/ \mathrm{N} / \mathrm{V}^{2}$ & $8.85 \times 10^{-12}$ \\
\hline$d_{o}$ & Characteristic droplet diameter $/ \mathrm{m}$ & $5.13 \times 10^{-7}$ \\
\hline$Q_{o}$ & Characteristic flowrate $/ \mathrm{m}^{3} / \mathrm{s}$ & $2.78 \times 10^{-12}$ \\
\hline$d$ & Droplet diameter $/ \mathrm{m}^{2}$ & $59-162 \mathrm{~nm}$ \\
\hline$Q$ & Experimental flowrate $/ \mathrm{m}^{3} / \mathrm{s}$ or $(\mathrm{ml} / \mathrm{h})$ & $2 \times 10^{-10}-2.8 \times 10^{-11}(0.75-0.1)$ \\
\hline
\end{tabular}

The maximum surface charge $\left(q_{s \max }\right)$ of the formed droplets is determined by the liquid properties as follows ${ }^{8}$ :

$$
q_{s \max }=0.53 \times 2^{1 / 2} \pi^{1 / 3}\left(\varepsilon_{o} \gamma^{2} \rho K^{2}\right)^{1 / 6}
$$

The charge of the droplets was estimated to be of $1.04 \times 10^{-3}$ Coulombs.

\section{S.4 Polymorphic ratio calculations}


1. Getting a reference sample to model and normalise the raw data

- A known sample of PCM form II and form I in a 1:1 ratio was made and analysed by PXRD.

- The reference sample was then analysed with GSAS2 to generate a table of peaks and their intensities.

- The highest peak that represented form I (26.420) and form II (24.0 20) from the reference sample was noted and used to get a peak intensity ratio for the exact same weight amount of both samples.

- It was found that the peaks corresponding to form I were approximately 4.25 times more intense than for form II.

- The 4.25: 1 (form I : form II) ratio was then used to calculate the actual ratios of form I and II in the raw data samples where the amounts of both polymorphs in each sample was unknown.

2. Getting the raw data values

- Each raw data sample was analysed with GSAS2 to generate a table of peaks and their intensities.

- The table was examined for a peak at 26.4 and $24.02 \theta$ and the resulting intensity recorded. If a peak was present at 26.4 form I was present in the sample, if a peak was present at 24.0 form II was present in the sample. The exact $2 \theta$ value for each of these peaks was recorded.

3. Calculating the normalised data values

- For each sample the intensity recorded for the raw data values was divided by either 4.25 or 1 depending on if that peak was representing form I $(26.4 \theta)$ or form II (24.0 2 $\theta)$ retrospectively

- These values are ratios of the amount of form I and form II in the sample

- The ratios were simplified.

The authors were unable to conduct a Rietveld refinement with the PXRD data, since the peaks observed had a severely asymmetric shape. This may be due to the particle size distribution of the samples or a misaligned detector. Integration of strong individual peaks that were representative of each polymorphic form were thus used as indicated above to calculate approximate polymorphic ratios with the software package GSAS.

\section{REFERENCES}

(1) Gaisford, S.; Buanz, A. B. M.; Jethwa, N., Characterisation of paracetamol form III with rapidheating DSC. J. Pharm. Biomed. Anal. 2010, 53, (3), 366-370.

(2) M.J. Abraham, D. v. d. S., E. Lindahl, B. Hess, and the GROMACS development team GROMACS User Manual version 2018. www.gromacs.org

(3) Oostenbrink, C. V., A.; Mark, A. E.; van Gunsteren, W. F, A biomolecular force field based on the free enthalpy of hydration and solvation: The GROMOS force-field parameter sets 53A5 and 53A6. J. Comput. Chem 2004, 25, 1656-1676.

(4) Koziara, K. B. S., M.; Malde, A. K.; Mark, A. E. , Testing and validation of the automated topology builder (ATB) version 2.0:Prediction of hydration free enthalpies. J. Comput.-Aided Mol. Des. 2014, 28, 221-233.

(5) Pothoczki. S, P. L., and Bakó. I, Molecular Dynamics Simulation Studies of the TemperatureDependent Structure and Dynamics of Isopropanol-Water Liquid Mixtures at Low Alcohol Content. . $J$. Phys. Chem. B 2019, 123, (35), 7599-7610.

(6) D, C. C. a. v. d. S., Picosecond Melting of Ice by an Infrared Laser Pulse: A simulation study. Angew. Chem. Int. Ed. 2008, 47, 1417-1420. 
(7) Gañán-Calvo, A. M.; Rebollo-Muñoz, N.; Montanero, J. M., The minimum or natural rate of flow and droplet size ejected by Taylor cone-jets: physical symmetries and scaling laws. New J. Phys. 2013, 15, (3), 13.

(8) Gañán-Calvo, A. M., The surface charge in electrospraying: its nature and its universal scaling laws. J. Aerosol Sci 1999, 30, 863-872. 